\title{
Interatividade em Ambientes Virtuais de Aprendizagem no processo de ensino e aprendizagem na Educação a Distância
}

\author{
Márcia Gorett Ribeiro Grossi* \\ Aline Lopes Moraes** \\ Amanda Tolomelli Brescia***
}

\begin{abstract}
Resumo
Com a ampliação e aperfeiçoamento da utilização de Ambientes Virtuais de Aprendizagem (AVAs) na Educação a Distância (EaD), percebe-se a necessidade de uma maior discussão sobre o potencial interativo das ferramentas que compõem esses ambientes. Assim, buscou-se nesta pesquisa verificar a importância da interatividade e afetividade no AVA Moodle e, ainda, delimitar as possibilidades e as limitações no desenvolvimento do processo de ensino e aprendizagem a distância, a partir da utilização de quarto ferramentas do Moodle. Para atingir esse objetivo foi realizada uma pesquisa descritiva, bibliográfica, de caráter exploratória. Os resultados revelam o quanto é indispensável às interações entre os participantes da $\mathrm{EaD}$ e que o tratamento dado aos alunos deve ser afetivo, já que o sentimento de pertença contribui significamente para uma aprendizagem pró-ativa e colaborativa.
\end{abstract}

Palavras-chave: Educação a Distância. Ambientes Virtuais de Aprendizagem. Moodle. Interatividade. Afetividade.

A s constantes transformações da sociedade, que hoje está sendo chamada de sociedade da informação ${ }^{1}$ ou do conhecimento e da inovação tecnológica, repercutiram em alterações significativas em diversos segmentos sociais, dentre eles, a educação.

A partir de tais mudanças, percebe-se a importância da educação em acompanhar, e sempre que necessário, intervir criticamente no que lhe concerne nessa nova ordem mundial, que tem como uma de suas principais características a utilização de Tecnologias da Informação e Comunicação (TICs), como forma de propagação de serviços e informações em âmbito mundial. Inclusive sendo, essas tecnologias, incorporadas no processo de ensino e aprendizagem há algum tempo, na educação presencial e, também, na Educação a Distância (EaD).

Nesse contexto, de modificações e da utilização das TICs na educação, a EaD surge como uma possibilidade de vir a ser uma modalidade de ensino inclusiva, porém, para isso é necessário mais que tecnologia, faz-se imprescindível que as instituições de políticas públicas auxiliem os alunos para se tornarem sujeitos autônomos, críticos e interventores nessa sociedade globalizada, aptos a se apropriarem das tecnologias educacionais, como explicam Moore e Kearsley (2007):

a ideia básica de educação a distância é muito simples: alunos e professores estão em locais diferentes durante todo ou grande parte do
*Professora Doutora em Ciência da Informação. Professora do Mestrado em Educação Tecnológica do CEFET-MG

**Especialista em Educação Profissional Técnica Integrada ao Ensino. Mestranda do Programa de Pósgraduação em Educação Tecnológica pelo CEFET-MG.

***Especialista em Planejamento, Implementação e Gestão da Educação Distância, Mestranda do Programa de Pós-graduação em Educação Tecnológica pelo CEFET-MG

${ }^{1}$ Conforme Moore (1999, p. 97) é difícil definir Sociedade de Informação, mas é possivel descrever características comuns a essa sociedade. Contudo, traz o entendimento de que Sociedade de Informação é uma sociedade na qual a informação é utilizada intencionalmente, como elemento da vida econômica, social, cultural e política. 
tempo em que aprendem e ensinam. Estando em locais distintos, eles dependem de algum tipo de tecnologia para transmitir informações e Ihes proporcionar um meio para interagir. (MOORE e KEARSLEY, 2007, p. 1).

Compreende-se, então, que, para a veiculação das atividades desenvolvidas num curso na modalidade a distância, faz-se necessário a utilização de ferramentas de interação e comunicação, quase sempre agrupadas nos denominados Ambientes Virtuais de Aprendizagem (AVAs). Moore e Kearsley (2007) também esclarecem que na Educação a Distância, a tecnologia é o meio de comunicação único ou principal, o que evidentemente não é o caso em uma sala de aula.

E quais tecnologias são estas? São, entre outras, as ferramentas que compõem os AVAs e que podem ser classificadas como síncronas ou assíncronas, sendo que essas possibilitam realizar interações, avaliações e/ou comunicações entre os alunos, os tutores, os professores, o material, e o próprio ambiente.

Conceituando-se interações síncronas, como:

comunicação interativa sem defasagem de tempo. É também um sistema no qual eventos que ocorrem regularmente em intervalos de tempo são mantidos em sintonia usando alguma forma de mecanismo eletrônico de registros de tempo. (MOORE e KEARSLEY, 2007, p. 356).

E interações assíncronas como:

literalmente, não síncrono; em outras palavras, não ocorrendo ao mesmo tempo e criando, portanto, uma comunicação com uma defasagem que permite aos participantes responder em uma ocasião diferente daquela em que a mensagem é enviada. (MOORE e KEARSLEY, 2007, p. 353).

Diante de tais pressupostos, buscou-se, nesta pesquisa, verificar a importância da interatividade e afetividade no ambiente Moodle e, ainda, delimitar as possibilidades e as limitações no desenvolvimento do processo de ensino e aprendizagem na EaD, a partir da utilização de algumas ferramentas desse ambiente.

Para atingir esse objetivo, foi realizada uma pesquisa, no segundo semestre de 2012, descritiva, bibliográfica, de caráter exploratória.

\section{Ambientes Virtuais de Aprendizagem (AVAs)}

O panorama político, econômico, social e, porque não, educacional da década de 2010 é caracterizado pela redução das fronteiras espaciais e temporais, tudo isso somente pôde ser efetivado, a partir das inovações tecnológicas. Essas possibilitam definir novos paradigmas no cenário econômico-político, e que, consequentemente, atingem também a abertura de novas perspectivas relacionadas à educação.

Surgem assim, os Ambientes Virtuais de Aprendizagem (em inglês, Learning Management Systems ou ainda em português, Sistemas de Gerenciamento de 
Interatividade em Ambientes Virtuais de Aprendizagem no processo de ensino e aprendizagem na Educação a Distância

Aprendizagem). Mattar (2011) acredita que os Ambientes Virtuais de Aprendizagem são a marca registrada da Educação a Distância, embora alguns estudiosos já estejam apontando que esses ambientes estejam ultrapassados e substituídos pelos Ambientes Virtuais de Ensino e Aprendizagem (AVEAs).

O AVEA é uma denominação mais abrangente do que a do AVA e que compreende as ações de ensino necessárias à aprendizagem. Para Nardin et al. (2009) o AVEA enfatiza e valoriza o papel do professor em organizar, planejar, implementar e avaliar as atividades didáticas no ambiente.

Os autores esclarecem que a diferença entre um AVA e um AVEA está nas potencialidades que o AVEA oferece para a comunicação e a interação em um contexto no qual a aprendizagem está vinculada ao ensino, enfatizando a intencionalidade pedagógica, constituindo um processo sistemático, organizado e institucional/formal (NARDIN et al.,2009).

Roncarelli (2007) reforça que a diferença entre esses ambientes está nos quatro pilares que os AVEA contemplam: sistematização, organização, intencionalidade pedagógica e caráter formal/institucional.

Ainda sobre o conceito recém formulado de AVEA, para Almeida (2003), os AVEAs permitem integrar múltiplas mídias e recursos, apresentar informações de maneira organizada, desenvolver interações entre pessoas e objetos de conhecimento, elaborar e socializar produções tendo em vista atingir determinados objetivos. Assim, - AVEA é uma plataforma que possui as disciplinas e seus conteúdos como todas as ferramentas que objetivam estabelecer comunicação e interação entre os envolvidos no processo de construção do conhecimento a distância.

Etimologicamente a palavra ambiente possui sua origem no latim ambiens, que significa "volta ao redor", do verbo ambire, "ir ao redor", de AMBI-, "em volta, ao redor", mais IRE, "ir". Sendo assim, pode-se compreender que se refere a tudo que está envolta ou envolve coisas e ou pessoas.

A palavra virtual deriva-se do latim medieval virtualis, que tem sua procedência em virtus, -utis, podendo designar qualidades do homem, coragem, energia, potência. E não apenas o oposto ao real, como senso comum costuma definir o termo virtual.

O AVA no espaço educacional destaca-se como uma promissora proposta pedagógica. Dessa forma, Amaral e Rossine (2008, p. 4) apud Gomes (2001, p. 25) classifica-o como:

ambiente virtual de aprendizagem é o ambiente tecnológico no ciberespaço que permite o processo de ensino aprendizagem através da medição pedagógica entre alunos ou um grupo de alunos e o professor ou um grupo de professores ou de outros agentes geograficamente dispersos. Apresenta-se em formas de portais, banco de dados, bibliotecas virtuais, cursos a distancia, museus ou outros. (GOMES, 2001, p. 25).

Também sobre o conceito de AVA, de acordo com Silva, (2009, p. 3) apud Almeida, 
os AVAs podem ser denominados como:

ambientes virtuais de aprendizagem são sistemas computacionais disponíveis na Internet, destinados ao suporte de atividades mediadas por tecnologias de informação e comunicação. Permitem integrar múltiplas mídias, linguagens e recursos, além disso, apresentam informações de maneira organizada, ampliam as interações entre as pessoas e objetos de conhecimento, propiciam ainda a socialização de experiências e produções. (SILVA, 2009, p.3).

A partir das exposições anteriores, pode-se aferir que, por Ambientes Virtuais de Aprendizagem, designam-se por uma proposta educacional, cujo objetivo está relacionado à possibilidade de interação entre sujeitos localizados em espaços físicos diferenciados, com o objetivo de edificação de aprendizagem colaborativa e mediada por diversos sujeitos sociais que atuam efetivamente para a construção do conhecimento. Dentre esses, pode-se citar a presença dos alunos, professores e tutores, todos empenhados no aperfeiçoamento do processo de ensino-aprendizagem e ainda do próprio ambiente e do material didático disponibilizado.

Contudo, os AVAs não podem ser considerados um ambiente de aprendizagem por si só, já que se tratam apenas de uma instalação - Sistemas de Gerenciamento de Aprendizagem (SGA), também denominados como plataformas de ensino a distância, em que são disponibilizados diversas mídias, linguagem e recursos, pois se não houver a noção de interatividade nessa plataforma o AVA será apenas mais um instrumento dentre tantos outros obsoletos na educação.

No mercado de produção de softwares educativos, existem muitos AVAs que auxiliam no desenvolvimento de metodologias educacionais, principalmente utilizando para isso a Internet. Muitas instituições produzem seu próprio ambiente (segundo o Censo EaD.br 2010, 33\% das instituições tem seu software de EaD totalmente desenvolvido internamente), algumas os disponibilizam para a comunidade acadêmica, como é o caso do TelEduc, que foi desenvolvido pelo Núcleo de Informática Aplicada à Educação (NIED) da Universidade Estadual de Campinas (UNICAMP) ou o AulaNet, pelo Laboratório de Engenharia de Software (LES), do Departamento de Informática da PUCRJ (Mattar, 2011), outras, ainda, resguardam-se e utilizam o AVA apenas internamente. Alguns outros exemplos de AVAs são o Moodle, o Solar, o Sócrates, dentre outros, que cada vez mais ganham espaço no Brasil e no exterior, colaborando assim com o processo educacional a distância.

A educação necessita acompanhar os novos modelos de propagação da informação e do conhecimento. Para isso, exige-se da educação propostas inovadoras que consolidem a edificação do conhecimento e que acompanhem as atuais mudanças. Uma das tendências mais recentes não apenas no Brasil, mas em todo o mundo, é a utilização de softwares gratuitos, livres e/ou de código aberto e, por esse motivo, foi escolhido como Ambiente Virtual de Aprendizagem a ser avaliado, neste artigo, o Moodle, tendo como principais ferramentas analisadas no que se refereàs possibilida- 
Interatividade em Ambientes Virtuais de Aprendizagem no processo de ensino e aprendizagem na Educação a Distância

des de interatividade: o fórum, o chat, a mensagem e a tarefa. Outra tendência é ainda, a integração dos AVAs a outras ferramentas da Web 2.0, como blogs, youtube, twitters, facebooks, entre outros. Ou seja, as tecnologias colaboram com a EaD, como postulado por Barros (2008):

a Educação a Distância (EaD) tem ao longo da história se transformado e com isso se colocado com uma alternativa para os dias atuais. Se no início, ela se prestava apenas a atender aos interesses econômicos vigentes na sociedade, de tal forma que o ensino era meramente unilateral (ensino por correspondência), focado na tecnologia utilizada para tal veiculação (correios, rádio) vencer a barreira da distância e qualificar massivamente a população eram seus objetivos. Hoje porém, a educação a distância amplia-se juntamente com as novas tecnologias e agrega novos valores pedagógicos e, por isso, pode constituir-se,como já foi dito,numa alternativa para a inclusão social. (BARROS, 2008 p.2).

Se, conforme foi citado, os Ambientes Virtuais de Aprendizagem não são autossuficientes apenas por existirem e por serem compostos pelos sujeitos da aprendizagem, materiais, entre outros, o que falta para que ele atinja seu objetivo que é o progresso da aprendizagem pelos sujeitos? A interação, que é o que será tratado no próximo tópico deste artigo.

\section{Interatividade: ação intrínseca a EaD}

A aprendizagem a distância reporta a um elemento indispensável para a sua concretização: a interatividade. No contexto da EAD o favorecimento da interação oportuniza novas relações com o conhecimento, já que nos AVAs o aluno tem a oportunidade de realizar escolhas e essas podem ser mediadas pelo uso de suportes e recursos tecnológicos.

Mussi e Haguenaur (2009, p.6) apud Anderson (2003, p. 129) definem a interação na educação a distância como:

um conceito complexo e multifacetado em todas as formas. Tradicionalmente interação focava na interação entre professores e alunos em sala de aula. Esse conceito foi expandido para incluir diálogos sincronizados à distancia (conferência de áudio e vídeo); formas assícronas de diálogo simulado e diálogo assíncrono mediado (conferência por computador e correio de voz); e respostas e retornos de objetos e dispositivos inanimados, tais como "programas de computador interativos" e 'televisão interativa'. (MUSSI, HAGUENAUR, 2009 p.6).

Para Moore e Kearsley (2007):

o ensino a distância eficaz depende de uma compreensão profunda da natureza da interação e de como facilitá-la por meio de comunicações transmitidas com base em tecnologia. Foram identificados três tipos distintos de interação: [...]

Interação Aluno-Conteúdo: [...] representa uma característica definidora da educação, que é um processo de aprendizado planejado de determinado conteúdo, auxiliado por um professor ou por professores. 
[...]

Interação Aluno-Instrutor: [...] Quando é possível a interação on-line do aluno [...], o aluno pode se valer da experiência do instrutor profissional, ao mesmo tempo em que interage com o conteúdo [...].

Interação Aluno-aluno: [...] Dois tipos diferentes de interação estão incluídos neste caso: internamente nos grupos e entre os grupos [...] interação de aluno para aluno em ambientes on-line, quando as pessoas não se reúnem face a face e seu grupo - se houver - é um grupo virtual. (MOORE e KEARSLEY, 2007, p. 152-153).

A partir desses conceitos, infere-se que o aluno da EaD é sujeito do processo de ensino-aprendizagem mediado por recursos tecnológicos e humanos, interagindo com o ambiente em que ele se encontra, com o professor, com o material didático e com os demais alunos, promovendo assim a aprendizagem.

Contudo, como já se percebe que a construção dos conhecimentos não ocorre de forma autônoma, ela perpassa o campo das relações sociais, na qual o educando pode compartilhar suas experiências adquiridas com outros atores sociais, a partir de uma aprendizagem colaborativa, a interação aluno-aluno descrita por Moore e Kearsley (2007). E esse processo torna-se cíclico, já que a partir da convivência virtual, os AVAs oportunizam as trocas de informações e (re)significam conceitos entre os estudantes, num movimento sucessivo, no qual cada um deixa sua marca e é marcado pelos outros.

Conforme Barbosa (2005) afirma:

os ambientes virtuais de aprendizagem não surgiram para superar a proposta de aula presencial e sim para acrescentar mais uma possibilidade de ensino-aprendizagem em moldes que a tecnologia pode proporcionar. Entretanto, seu uso só se faz articulado com os fins pedagógicos de uma cultura do aprender a aprender, pela mediação feita pelo professor, pelos colegas, pela linguagem e pelo próprio ambiente. Assim, entra em cena a mediação tecnológica articulada ao processo educativo e a inserção paulatina da Internet como veículo de comunicação importante para a Educação. (BARBOSA, 2005, p. 26).

Sendo que esta mediação tecnológica articulada ao processo educativo é o que está sendo chamado de interação neste artigo.

Ainda de acordo com Mussi e Haguenaur (2009) citados por Silva (2001):

interatividade significa libertação do constrangimento diante da lógica da transmissão que dominou no século XX. É o modo de comunicação que vem desafiar a mídia de massa - rádio, cinema imprensa e TV a buscar a participação do público para se adequar ao movimento das tecnologias interativas. É o modo de comunicação que vem desafiar professores e gestores da educação, igualmente centrados no paradigma da transmissão, a buscar a construção da sala de aula onde a aprendizagem se dá com a participação e cooperação dos alunos [...] Vivemos a transição do modo de interação massivo para o interativo. (SILVA, 2001, p.1).

Sendo assim, cabe aos educadores superar a visão de se denominarem como mestres detentores dos saberes universais em relação aos alunos, vistos como aqueles seres pacíficos e ávidos pelo conhecimento do mestre, pois a aprendizagem individual está também subordinada às interações sociais realizadas no AVA. 
Moore e Kearsley (2009, p. 156) transcrevem um Quadro 1 de Hierarquia da interação de Roblyer e Wiencke (2003) que pode ser um bom demonstrativo da hierarquia da interação em AVAs, sendo:

Quadro 1: Hierarquia da interação

\begin{tabular}{|c|c|c|c|c|c|}
\hline Escala & $\begin{array}{l}\text { Criação de } \\
\text { relacionamentos } \\
\text { sociais para a } \\
\text { interação }\end{array}$ & $\begin{array}{c}\text { Meios de } \\
\text { instrução para } \\
\text { a interação }\end{array}$ & $\begin{array}{c}\text { Interatividade } \\
\text { dos recursos } \\
\text { de tecnologia }\end{array}$ & $\begin{array}{c}\text { Prova de } \\
\text { interesse do } \\
\text { aluno }\end{array}$ & $\begin{array}{c}\text { Prova de } \\
\text { interesse } \\
\text { do instrutor } \\
\text { (professor e/ou } \\
\text { tutor) }\end{array}$ \\
\hline $\begin{array}{l}\text { Qualidade } \\
\text { de } \\
\text { interação } \\
\text { reduzidas }\end{array}$ & $\begin{array}{l}\text { Não há incentivo } \\
\text { da interação dos } \\
\text { alunos, no sentido } \\
\text { social do termo. } \\
\text { Nenhuma das } \\
\text { atividades requer } \\
\text { interações sociais } \\
\text { ou estão limitadas } \\
\text { a introdução } \\
\text { breves no início } \\
\text { do curso. }\end{array}$ & $\begin{array}{l}\text { As atividades } \\
\text { não exigem } \\
\text { interação do } \\
\text { instrutor com } \\
\text { alunos e vice } \\
\text { versa; ocorre } \\
\text { transmissão de } \\
\text { informações. }\end{array}$ & $\begin{array}{l}\text { Fax, página na } \\
\text { web ou outros } \\
\text { recursos } \\
\text { tecnológicos } \\
\text { permitem a } \\
\text { veiculação de } \\
\text { informações } \\
\text { em só um } \\
\text { sentido. }\end{array}$ & $\begin{array}{l}50 \% \text { a } 75 \% \\
\text { respondem } \\
\text { às mensagens } \\
\text { do instrutor, } \\
\text { quando solici- } \\
\text { da; estas quase } \\
\text { só têm relação } \\
\text { com os tópicos } \\
\text { e tendem a } \\
\text { serem breves e } \\
\text { dispersas. }\end{array}$ & $\begin{array}{l}\text { Instrutor não } \\
\text { responde } \\
\text { todos os } \\
\text { questionamentos } \\
\text { dos alunos, } \\
\text { demorando cerca } \\
\text { de } 48 \text { horas; a } \\
\text { resposta dada } \\
\text { é vaga e não } \\
\text { oferece subsídios } \\
\text { para os alunos. }\end{array}$ \\
\hline $\begin{array}{l}\text { Qualidade } \\
\text { de } \\
\text { interação } \\
\text { mínimas }\end{array}$ & $\begin{array}{l}\text { Além de } \\
\text { introduções } \\
\text { breves, o instrutor } \\
\text { requer outro } \\
\text { intercâmbio de } \\
\text { informações } \\
\text { pessoais entre } \\
\text { os alunos, como } \\
\text { biografia por } \\
\text { escrito contendo } \\
\text { formação e } \\
\text { experiência } \\
\text { pessoal. }\end{array}$ & $\begin{array}{c}\text { Atividades } \\
\text { exigem que } \\
\text { os alunos se } \\
\text { comuniquem } \\
\text { com o instrutor } \\
\text { apenas } \\
\text { individual- } \\
\text { mente. }\end{array}$ & $\begin{array}{c}\text { E-mail, listserv, } \\
\text { conferência/ } \\
\text { quadro de } \\
\text { avisos. A } \\
\text { troca de } \\
\text { informações } \\
\text { acontece é } \\
\text { assíncrona }\end{array}$ & $\begin{array}{l}50 \% \text { a } 75 \\
\text { respondem } \\
\text { mensagens, por } \\
\text { conta própria } \\
\text { ou quando } \\
\text { solicitados, que } \\
\text { tem relação } \\
\text { com os tópicos, } \\
\text { muitas vezes, } \\
\text { são breves ou } \\
\text { dispersas. }\end{array}$ & $\begin{array}{c}\text { O instrutor } \\
\text { responde a } \\
\text { maior parte } \\
\text { das perguntas } \\
\text { no intervalo } \\
\text { de } 48 \text { horas; o } \\
\text { feedback algumas } \\
\text { vezes oferece } \\
\text { uma análise do } \\
\text { trabalho do aluno } \\
\text { e sugestões de } \\
\text { melhoria. }\end{array}$ \\
\hline $\begin{array}{l}\text { Qualidade } \\
\text { de } \\
\text { interação } \\
\text { moderadas }\end{array}$ & $\begin{array}{c}\text { O instrutor } \\
\text { proporciona troca } \\
\text { de informações } \\
\text { pessoais entre os } \\
\text { alunos, oferece } \\
\text { pelo menos } \\
\text { uma atividade } \\
\text { em grupo para } \\
\text { aumentar a } \\
\text { comunicação e o } \\
\text { relacionamento } \\
\text { social entre os } \\
\text { alunos. }\end{array}$ & $\begin{array}{l}\text { Atividades } \\
\text { exigem que } \\
\text { alunos se } \\
\text { comuniquem } \\
\text { com o instrutor } \\
\text { e entre si. }\end{array}$ & $\begin{array}{l}\text { E-mail, listserv, } \\
\text { conferência/ } \\
\text { quadro de } \\
\text { avisos e } \\
\text { intercâmbios } \\
\text { síncronos de } \\
\text { informações, } \\
\text { quase sempre } \\
\text { por escrito. }\end{array}$ & $\begin{array}{l}90 \% \text { a } 100 \% \\
\text { respondem às } \\
\text { mensagens do } \\
\text { instrutor e dos } \\
\text { outros alunos; } \\
\text { as respostas } \\
\text { sempre são } \\
\text { relacionadas a } \\
\text { tópicos, mas } \\
\text { algumas vezes } \\
\text { são breves. }\end{array}$ & $\begin{array}{c}\text { O instrutor } \\
\text { responde a } \\
\text { maior parte } \\
\text { das perguntas } \\
\text { no intervalo } \\
\text { de } 48 \text { horas; o } \\
\text { feedback algumas } \\
\text { vezes oferece } \\
\text { uma análise do } \\
\text { trabalho do aluno } \\
\text { e sugestões de } \\
\text { melhoria. }\end{array}$ \\
\hline
\end{tabular}




\begin{tabular}{|c|c|c|c|c|c|}
\hline $\begin{array}{l}\text { Qualidade } \\
\text { de } \\
\text { interação } \\
\text { acima da } \\
\text { média }\end{array}$ & $\begin{array}{c}\text { O instrutor, além } \\
\text { de proporcionar } \\
\text { o intercâmbio } \\
\text { de informações } \\
\text { pessoais entre } \\
\text { os alunos e } \\
\text { incentivar a } \\
\text { comunicação e a } \\
\text { interação social, } \\
\text { também interage } \\
\text { com os alunos em } \\
\text { uma base social/ } \\
\text { pessoal. }\end{array}$ & $\begin{array}{l}\text { Atividades } \\
\text { exigem que } \\
\text { alunos se } \\
\text { comuniquem } \\
\text { com o instrutor } \\
\text { e entre si. } \\
\text { Atuando } \\
\text { cooperativa- } \\
\text { mente e } \\
\text { compartilhando } \\
\text { os feedback. }\end{array}$ & $\begin{array}{c}\text { Além das } \\
\text { tecnologias } \\
\text { usadas para o } \\
\text { intercâmbio } \\
\text { síncrono e } \\
\text { assíncrono de } \\
\text { informações } \\
\text { escritas, } \\
\text { usam a } \\
\text { teleconferência, } \\
\text { e comunicação } \\
\text { visual em um } \\
\text { sentido e de } \\
\text { voz em dois. }\end{array}$ & $\begin{array}{c}50 \% \text { a } 75 \% \\
\text { respondem } \\
\text { e enviam } \\
\text { mensagens, } \\
\text { quando } \\
\text { solicitados e } \\
\text { voluntariamente, } \\
\text { relativas aos } \\
\text { tópicos e, } \\
\text { geralmente, } \\
\text { refletem a } \\
\text { intenção de } \\
\text { se comunicar } \\
\text { bem. }\end{array}$ & $\begin{array}{l}\text { O instrutor } \\
\text { responde a todas } \\
\text { as perguntas, } \\
\text { geralmente } \\
\text { imediatamente, } \\
\text { no intervalo } \\
\text { de } 24 \text { horas; o } \\
\text { feedback sempre } \\
\text { oferece uma } \\
\text { análise detalhada } \\
\text { do trabalho do } \\
\text { aluno e sugestões } \\
\text { para melhora. }\end{array}$ \\
\hline $\begin{array}{l}\text { Qualidade } \\
\text { de } \\
\text { interação } \\
\text { de alto } \\
\text { nível }\end{array}$ & $\begin{array}{c}\text { Proporciona } \\
\text { intercâmbio de } \\
\text { informações } \\
\text { e incentiva a } \\
\text { interação aluno- } \\
\text { aluno e instrutor- } \\
\text { aluno, o instrutor, } \\
\text { oferece estruturas } \\
\text { permanentes } \\
\text { do curso, cuja } \\
\text { finalidade é } \\
\text { promover o } \\
\text { contato social } \\
\text { entre alunos e } \\
\text { instrutor. }\end{array}$ & $\begin{array}{l}\text { Atividades } \\
\text { exigem que } \\
\text { alunos se } \\
\text { comuniquem } \\
\text { com o instrutor } \\
\text { e entre si. } \\
\text { Atuando } \\
\text { cooperativa- } \\
\text { mente e } \\
\text { mpartilhando } \\
\text { os feedback. }\end{array}$ & $\begin{array}{c}\text { Além das } \\
\text { tecnologias } \\
\text { que permitem } \\
\text { intercâmbio } \\
\text { de textos nos } \\
\text { dois sentidos, } \\
\text { vídeo nos } \\
\text { dois sentidos } \\
\text { ou as vídeo- } \\
\text { conferência } \\
\text { permitem } \\
\text { comunicações } \\
\text { síncronas } \\
\text { vocal/ visual } \\
\text { entre todos os } \\
\text { participantes. }\end{array}$ & $\begin{array}{l}90 \% \text { a } 100 \% \\
\text { respondem } \\
\text { ou enviam } \\
\text { mensagens, } \\
\text { sendo que } \\
\text { estas são } \\
\text { detalhadas e } \\
\text { relacionadas } \\
\text { aos tópicos. }\end{array}$ & $\begin{array}{c}\text { O instrutor } \\
\text { responde a todas } \\
\text { as perguntas, } \\
\text { geralmente } \\
\text { imediatamente, } \\
\text { no intervalo } \\
\text { de } 24 \text { horas; o } \\
\text { feedback oferece } \\
\text { uma análise } \\
\text { detalhada do } \\
\text { trabalho do aluno } \\
\text { e sugestões } \\
\text { para melhora, } \\
\text { com dicas e } \\
\text { informações } \\
\text { adicionais. }\end{array}$ \\
\hline
\end{tabular}

Fonte: Adaptado de Roblyer e Wiencke (2003) em Moore e Kearsley (2009, p. 156).

Analisando os dados apresentados no Quadro 1 e refletindo sobre qualquer turma de EaD, pode-se perceber que para existir uma boa interação e assim uma aprendizagem que envolva os alunos, é preciso que: os feedbacks sejam rápidos e constantes; os professores e tutores tenham atitudes pró-ativas e demonstrem preocupação com o aluno e com o curso, ou seja, tenham comprometimento; um bom suporte tecnológico.

Além disso, a aprendizagem precisa ser significativa para o aluno. Portanto o aluno precisa compreender a relevância do conteúdo e das atividades, suas significâncias e suas aplicabilidades práticas.

Outro ponto fundamental, em um curso em que os alunos e professores estãoseparados fisicamente, é tornar o ambiente virtual de aprendizagem o mais agradável e funcional para os alunos. Assim, a importância do design instrucional, que é o profissional responsável pelo tratamento dos conteúdos, sua formatação e suporte quanto ao uso dos recursos midiáticos, proporcionando assim uma boa interatividade.

Dessa forma, ao compreender que a construção do conhecimento ocorre a partir das relações sociais, da interação social entre os sujeitos (alunos-alunos e alunos-professores) 
Interatividade em Ambientes Virtuais de Aprendizagem no processo de ensino e aprendizagem na Educação a Distância

e entre esses e os suportes tecnológicos, o professor pode utilizar-se desses saberes para pensar estratégicas didáticas que orientem os objetivos do curso para atividades que contemplem a maior interação entre os educandos, que instigue o pensamento reflexivo e que fomente a criação, originando, assim, inúmeras possibilidades de aprendizagem que respeite e considere os conhecimentos do aluno e que estabeleça relações com os conteúdos pedagógicos do curso.

\section{Estratégias pedagógicas por uma interface interativa}

Modular Object-Oriented Dynamic Learning Environment (em português é um sistema modular de ensino a distância orientado a objetos), popularmente conhecido por Moodle é um software livre, ou seja, pode ser usado, copiado e redistribuído sem restrições, sendo que a sua principal função é apoiar o processo de ensinoaprendizagem, sendo um Ambiente Virtual de Aprendizagem. De acordo com Barros (2008):

o Moddle é dotado de uma interface simples, seguindo uma linha de portal. As páginas dos cursos são divididas em três colunas que podem ser personalizadas pelo professor, inserindo elementos em formatos de caixa como: Calendário, Usuários online, Lista de Atividades, dentre outros. Pelo fato de ser um software livre, gratuito e aberto, o Moodle pode ser carregado, utilizado e distribuído. Ele é um projeto de desenvolvimento contínuo, por isso podemos receber atualizações constantes, tendo como os própios usuários com seus construtores. Por propor uma aprendizagem colaborativa online, ele é considerado um ambiente baseado numa proposta sócio-construtivista.(BARROS, 2008, p.5)

Essa oportunidade de flexibilidade e customização é uma característica marcante do Moodle o que contribuiu para o seu crescimento exponencial, e a sua popularidade, segundo Alves et al. (2009), atualmente existem 45.816 usuários cadastrados e o Moodle está presente em 198 países, e mais de 200 instituições brasileiras estão utilizando esse ambiente como espaço de aprendizagem. Tudo isso, apenas comprova o grande interesse de educadores, estudantes e pesquisadores a se empenharem cada vez mais na utilização do Moodle, como possibilidade de estratégias pedagógicas que (re)significam olhares para a EaD e favorecem novos caminhos de interação e de aprendizagem nesse ambiente.

Como exposto anteriormente, o AVA não é um ambiente monológico ou autossuficiente na aquisição da aprendizagem, essa ocorre fundamentalmente a partir da instauração de interações entre os sujeitos sociais ao longo do processo educacional. Interações essas que serão discutidas no decorrer deste artigo a partir da análise de algumas ferramentas em suas possibilidades e limitações.

No ambiente Moodle, pode-se citar exemplos de ferramentas de comunicação síncronas fóruns, mensagem e tarefa. Opostamente a esse modelo, a comunicação 
síncrona tem como exemplo os chats. Na próxima seção deste artigo será tratadas as peculiaridades de cada ferramenta.

\section{Ferramentas do Moodle: possibilidades e limitações nas interações do processo educativo}

O relacionar-se virtualmente vem sendo abordado em inúmeros trabalhos científicos e não-científicos e uma das discussões que mais tem sido abordadas é a de que os alunos precisam da interação com o professor não apenas para que o este "deposite" seu saber naquele, como Paulo Freire trata em seu conceito de educação bancária, mas, principalmente para que exista a troca de informações, de vivências, ou seja, a interação real entre eles.

No Moodle, pode-se encontrar diferentes tipos de ferramentas que auxiliam no processo comunicativo entre os sujeitos que utilizam este AVA. Os momentos de interatividade no AVA são indispensáveis para o processo educacional, pois eles estimulam aspectos relacionados a sociabilidade entre os usuários e ainda realça um sentimento de acolhimento, já que o aluno tem a certeza de que existe alguém naquele ambiente (mesmo distante fisicamente) com quem possa compartilhar dúvidas, anseios e angústias no decorrer de sua trajetória educacional.

As ferramentas do Moodle contemplam também a classificação que foi discutida anteriormente de síncronas ou assíncronas. A escolha de uma ou outra ferramenta depende dos objetivos da proposta educativa.

Normalmente, as ferramentas síncronas são menos utilizadas na Educação a Distância, por exigir que estejam online tutores (ou professores) e cursistas no mesmo momento, o que pode ser difícil nessa modalidade de ensino, portanto, opta-se mais comumente pelas ferramentas assíncronas, que não exigem retorno imediato por parte dos educadores.

Cabe ao professor adequar o uso da ferramenta de acordo com seus objetivos.

Dentre as ferramentas discutidas neste artigo, dar-se-á destaque para: fórum, tarefa e mensagem (ferramentas assíncronas) e chat (síncrona), que apresentam as caracacterizações a seguir.

a) fórum: ferramenta considerada por alguns autores, como Nakamura (2008) como a principal do ambiente Moodle, pois é utilizada para discussões acerca de algum tema pré determinado, debate em torno de leitura aplicáveis a disciplina do curso, ou ainda, a simples troca de informações possibilitando a construção do conhecimento coletivo, da inteligência coletiva descrita por Levy (1996).

Geralmente o tutor inicia o fórum com uma questão e posteriormente os alunos deverão reponder de forma sucinta e, com suas palavras, sua opinião e impressão sobre o assunto. Os fóruns assemelham-se às listas de discussões, pois os participantes possuem acesso às mensagens postadas pelos outros usuários, e todos respondem 
assincronamente, ou seja, não é necessário que os outros usuários estejam conectados ao mesmo tempo no ambiente para postar a mensagem.

Outra possibilidade muito utilizada dessa ferramenta é a divulgação de informações e armazenamento de tais informes no ambiente virtual de aprendizagem, por meio de um fórum que pode ser chamado de "Fórum de notícias", por exemplo. Ou ainda, a possibilidade de um espaço para conversas informais no AVA, que em muitos cursos é conhecido por "Sala do cafezinho", espaço esse que os cursistas tem a liberdade para tratarem de assuntos diversos e alheios ao curso que está acontecendo em outras ferramentas do ambiente.

Mattar (2011) descreve que os fóruns podem ser moderados (quando o professor ou tutor, lê as mensagens postadas pelos cursistas e aprova ou não sua publicação) ou livres (tudo o que os cursistas escrevem é publicado), embora esta opção não exista ainda no Moodle. Outra configuração possível de ser feita é a criação de novos tópicos pelos cursistas ou apenas pelos tutores que atuam na disciplina.

Recomenda-se que a atuação do tutor junto ao fórum seja dialógica, para que os cursistas não percebam essa ferramenta, apenas como mais um local de entrega de tarefas (como acontece na ferramenta Tarefa), mas sim, um espaço de diálogo constante, de novas indagações, questionamentos, e de contribuições dos demais colegas para uma determinada questão ou fato.

Mattar (2011) ainda faz a seguinte sugestão de funcionamento dessa ferramenta:

nos fóruns chamados role-playing (ou interpretação de papéis), os alunos assumem determinados papéis ao preparar suas respostas, mais otimistas ou pessimistas, de advogados do diabo etc. Alguns alunos podem ser responsáveis pelo pontapé inicial, resumindo um texto e propondo questões para a discussão. Outros podem, também, ficar responsáveis por resumir e encerrar um debate apontando, por exemplo, questões que ainda permanecem abertas. (MATTAR, 2011, p. 24-25).

Fica claro, nessa proposta, que os papéis de alunos e professores confundemse e que, em algum momento, os alunos podem ocupar o posto de um professor que encerra o debate ou que o instiga. Essa é uma forte tendência na utilização dessa ferramenta.

Outro aspecto que o tutor deve ficar atento é para que este não se ausente completamente do debate, dando, assim, a sensação de abandono aos alunos e nem participe demais, sufocando-os ou ainda tolhendo suas opiniões.

b) mensagem: ferramenta disponível para favorecer a comunicação entre alunos, tutor e formadores. Essa ferramenta funciona tipicamente como um e-mail pessoal contemplando a interface assíncrona. O usuário manda a sua mensagem e, posteriormente, irá receber a resposta em sua caixa de entrada de mensagem.

Um ponto positivo dessa ferramenta, é a possibilidade de uma comunicação 
privativa entre alunos/alunos e professores/alunos, pois, mesmo que o professor encaminhe uma mesma mensagem a todos os alunos, ao respondê-la, o aluno tem a opção de encaminhar apenas ao professor sua resposta, ou ainda de iniciar um diálogo individualizado.

Essa é uma ferramenta com um diferencial que apenas o fórum possui (dependendo de sua configuração), que é a comunicação, a interação, mesmo sem que o receptor da mensagem esteja online no AVA, pois, ao enviar uma mensagem, a mesma é encaminhada em cópia para o e-mail anteriormente cadastrado.

c) tarefa: essa ferramenta possui variações de configuração internas, mas, tem como resultado interfaces e possibilidades de interações muito parecidas, além de possuir uma interação assíncrona.

Nessa ferramenta o professor irá disponibilizar aos alunos as atividades a serem realizadas ao longo da dispiciplina. No enunciado, o professor poderá descrever os critérios para a avaliação da tarefa, dentre eles, a data e o horário limite para a postagem da atividade.

Nesse espaço, o aluno anexa seu trabalho, caso seja realizado em um outro programa, ou, então, existe ainda o recurso de adicionar a atividade no próprio Moodle, dependendo da configuração escolhida.

Uma potencialidade que essa ferramenta possui e que precisa ser mais explorada pelos tutores é o feedback de tarefas. Não apenas a nota e um pequeno comentário, esta pode propiciar, também, o envio do arquivo comentado e as correções necessárias no corpo do texto encaminhado pelo cursista. Assim, aumenta a interação entre cursistas e tutores e auxilia na compreensão dos erros cometidos pelos cursistas.

d) chat: ferramenta de interatividade, é manuseada de forma síncrona, sendo assim, permite um diálogo em tempo real entre alunos, tutores e professores. Uma estratégia de utilização pode ocorrer a partir da realização de uma leitura prévia, debatendo posteriormente com os os alunos pontos chave do texto.

Outro emprego comum é tirar dúvidas gerais relacionadas à matéria estudada. Nesse caso, não é realizada uma leitura prévia, mas o professor ou o tutor devem ter pleno domínio do conteúdo, para que as dúvidas sejam sanadas online. Um cuidado necessário, nesse caso, é para o tamanho do grupo que participará em cada horário disponibilizado de chat, pois um grupo muito grande pode deixar o tutor ou professor "perdidos", e os alunos também, em meio a tantos questionamentos.

Os horários para a ocorrência desses eventos são dirigidos pelos tutores e professores, ou ainda, em conjunto com os alunos pela ferramenta "Escolha", que possibilita a realização de uma espécie de enquete entre os envolvidos. Nessa mesma ferramenta, há a possibilidade de estar exposto o tema norteador do chat. No dia e 
horário marcados, todos os participantes entram na sala ao mesmo tempo e discutem a respeito do tema proposto.

Chats livres também podem ser disponibilizados aos alunos sem que, necessariamente, tenham a presença do tutor ou professor, efetuando-se como ponto de encontro online dos alunos, sendo assim, o bate papo pode ser utilizado em outros horários, sem a necessidade da presença de um mediador.

Por exigir domínio completo da matéria estudada e agilidade no raciocínio e na digitação, essa ferramenta encontra, ainda, algumas barreiras junto aos professores e tutores como, por exemplo, dificuldade da utilização da tecnologia de maneira ágil.

Contudo, o Moodle é um ambiente muito rico em propostas pedagógicas que contribuem para o desenvolvimento do processo de ensino-aprendizagem, cabendoao professor e ao tutor adequarem a escolha da ferramenta à proposta pedagógica e aos objetivos específicos da disciplina, sendo possível alcançar experiências sólidas e significativas de interação que determinam o sucesso de cursos a distância.

\section{Possibilidades e desafios: a interatividade na $\mathrm{EaD}$ a partir da afetividade}

A partir das descrições das ferramentas do Moodle, pode-se fazer uma análise de como essas podem otimizar as ações pedagógicas nesse AVA, e, ainda, como as relações constituídas podem ser permeadas pela afetividade.

Afetividade e o sentimento de pertença são indispensáveis em quaisquer atividade humana, dentre elas, pode-se destacar a educação, em especial na modalidade a distância, pois muitos alunos ainda têm a ideia de que a $\mathrm{EaD}$ é uma modalidade de educação "fria", na qual o docente estuda sozinho e não o tem apoio do professor.

Nos cursos a distância, os encontros presenciais geralmente são poucos (e tendem a ser cada vez menos com a evolução da tecnologia), o que delimita a sua principal característica, uma educação quase que predominantemente a distância. A ausência do contato físico humano, muitas vezes, pode ser um desafio para alunos dessa modalidade, que na dificuldade de superar esse obstáculo, acabam evadindo-se de seus cursos.

Segundo Pallof e Pratt (2002), expressar sentimentos online é uma tarefa difícil, porém, não impossível. Nos espaços escolares dos cursos presenciais as manifestações de sentimento podem ser interpretadas a partir das expressões faciais, corporais, entonação de voz, dentre outros elementos, que podem compor laços de afetividade entre os sujeitos envolvidos no processo educaional. Contudo, nos curso EaD esses recursos não podem ser desfrutados como na sala de aula física, em contrapartida eles não podem deixar de existir como prática educativa.

A partir do manuseio das ferramentas de interatividade, pode-se solidificar o laços afetivos entre usuários de um AVA. Afetividade ao contrário do que o senso comum muitas vezes relata, não refere-se apenas às manifestações físicas de carinho, 
emoção, ternura e simpatia. Ela também pode ser concebida a partir da vivência e da interação, e esta não necessariamente necessita ser física, poderá ocorrer também nos espaços virtuais.

A afetividade, entendida como promotora de emoções facilitadoras do processo de ensino-aprendizagem, poderá acontecer a partir do desenvolvimento de atividades em grupo, por exemplo.

As ferramentas Chat e Fórum podem ser caracterizadas como importantes canais de comunicação que permitem a reunião de um grupo de estudantes para o debate de questões concernentes ao curso. A diferença entre elas é que, a primeira, é realizada num movimento síncrono e, a segunda, assincronamente.

O fórum como instrumento pedágogico é um recurso que otimiza o processo educativo, por privilegiar a concepção dialógica de aprendizagem e de liberdade de expressão. Nesse espaço, o aluno poderá manifestar de forma menos formal suas concepções, opiniões e impressões sobre o tema discutido, participando de forma mais ativa, além de ainda ser estimulado a interagir com outras pessoas, fortalecendo, assim, a concepção de grupo, de reflexão, de respeito a opinião do outro, de ética, dentre outros valores fundamentais num espaço de aprendizagem.

Contudo, cabe ressaltar que também no AVA faz-se imprecindível a presença de um mediador do debate, para que, com isso, possa-se evitar alguns problemas como: a transmissão (proposital ou ingênua) de concepções preconceituosas entre os participantes; que as discussões fujam ao tema inicialmente proposto; e que não ocorram ofensas e a utilização de palavras de baixo calão entre os participantes do fórum, ou seja, ações não educacionais, seja na educação presencial ou a distância. Outro cuidado que o mediador deve ter refere-se ao "erro" do aluno, em como publicar isso, sem contudo, constrangê-lo publicamente. Para evitar esse tipo de problema, o tutor poderá intervir utilizando a ferramenta mensagem.

Em relação a ferramenta Chat, a concepção de interação é essencial. O chat pode ser utilizado como um recurso adicional a aprendizagem, pois privilegia, nesse espaço, uma aprendizagem que alivia os alunos quanto a pressões nas atividades escritas, formais e notas. Outro aspecto positivo quanto ao seu uso é a sua capacidade de socialização entre alunos, tutores e professores, permitindo que os participantes opinem, vejam a opinião dos outros e compartilhem suas experiências.

O grande desafio do mediador do chat vai ao encontro daqueles destacados no fórum e, ainda, pode-se destacar: na ocorrência de algum mal entendido entre os participantes, esse poderá ser resolvido em tempo real, não alimentando, assim, nenhum ressentimento a ser resolvido a posteriori, a necessidade de ser incisivo quando algum aluno parecer monopolizar a discussão, ser direto nos momentos em que o grupo estiver intensificando indesejavelmente o ritmo das discussões e, ainda, se evite a concentração das discussões entre aqueles que possuem melhores destrezas de digitação. O moderador do chat deve estar preparado para tais ocorrências e com 
muita tranquilidade e segurança deve reconduzir a discussão ao encontro dos objetivos iniciais propostos.

Na ferramenta Tarefa, vista numa pespectiva pedagógica, o aluno poderá ter um espaço mais individualizado na exposição de sua atividade, pois, nessa ferramenta, há o recurso do aluno compartilhar com os outros alunos ou somente com o formador do seu trabalho. Como espaço para avaliação, é uma ótima ferramenta, pois o tutor e ou professor podem examinar a trajetória de construção de aprendizagem.

A última ferramenta analisada é a Mensagem, sendo que ela possui as mesmas propriedades de um e-mail, dentre elas, as inúmeras potencialidades de interação entre os usuários do ambiente virtual. Cabe ressaltar que tudo o que é escrito em alguma ferramenta do AVA é registrado para fins de histórico de acesso, sendo somente publicado aquilo que diz respeito ao coletivo.

Nesse sentido, isso poderá ser um desafio para os alunos do curso e para o tutor, pois os alunos podem se sentir enganosamente coagidos, ao realizarem seus questionamentos ou compartilharem seus anseios, com receio de que estejam sendo criticados por "alguém que tem acesso a tudo". Em relação ao tutor, esse desafio está relacionado a oportunidade de obterem informações (sem restrições) do aluno e da sua trajetória educacional.

\section{Considerações finais}

Analisando os achados de pesquisa, pode-se afirmar que a principal possibilidade no desenvolvimento do processo de ensino e aprendizagem em EaD, está em oferecer flexibilidade, customização e variedade de estratégias pedagógicas que as diversas ferramentas que compõem os AVAs possuem.

No que se refere às limitações, o AVA não pode ser considerado ambiente de aprendizagem por si só, sem interação, essa ferramenta é apenas mais uma dentre outras, obsoletos na educação.

Também, neste estudo, procurou-se explorar as quatro ferramentas do Moodle mais utilizadas nos cursos de EaD, e sua importância para o processo de aprendizagem, sendo função do professor e/ou tutor adequar o uso dessas ferramentas aos objetivos pedagógicos do curso, sempre auxiliado por outros atores envolvidos nessa modalidade de ensino, como o design instrucional.

Nesse sentido, é perceptível o quanto é indispensável as interações e as afinidades entre os participantes sejam professores, alunos e tutores, ou seja, todos aqueles que compõem a unidade do curso e que contribuem para que o aluno se sinta como parte integrante do processo educativo. Uma vez que a construção do conhecimento ocorre a partir das relações sociais, da interação social entre os sujeitos.

Empenhou-se em demostrar neste artigo, que as manifestações interativas constituem o novo cenário educativo da EaD, e que o tratamento dado aos alunos 
deve ser afetuoso, já que o sentimento de pertença contribui significamente para uma aprendizagem pró-ativa e colaborativa. Junior, Massensini e Neves (2010) determinam a importância da interatividade:

é necessário entender que a modalidade $\mathrm{EaD}$ não se constitui por um ambiente online com um amontoado de informações disponíveis ao aluno. É necessário que haja a adequação pedagógica do conteúdo, metodologia própria e uma equipe educacional especializada para a mediação entre o conhecimento e os estudantes. Nos cursos online a interação professor/aluno é considerada como parte essencial para a efetivação do processo de ensino-aprendizagem.(JÚNIOR, MASSENSINI e NEVÉS, 2010, p. 3).

Indiscutivelmente, a interatividade possibilita a otimização da qualidade do processo educacional. E uma de suas características fundamentais, é que ela deve ser permeada pela afetividade. Assim, como o aluno do ensino presencial que requer dos professores emoção, alegria na construção do conhecimento, o aluno da EaD necessita de acordo com Bonnatto, Martins, Ramos, Santos e Silva (2008) de:

a consideração das emoções nos processos de ensino aprendizagem a distancia deve incluir: a)criação de motivos significativos à pessoa humana no início, meio e fim das atividades individuais e colaborativas; b) o fortalecimento de afetividade e cumplicidade na superação de desafios de aprendizagem individual e coletiva; c) o reconhecimento e valorização aberta das emoções e 'lições aprendidas' com o grupo e com a vida (testemunho pessoal). (BONNATTO, MARTINS, RAMOS, SANTOS e SILVA 2008, p.5).

Não existiu a pretensão de esgotar esse assunto com este estudo, mas sim de iniciar a discussão sobre a afetividade e interatividade entre os componentes (materiais e humanos) de cursos de EaD.

\begin{abstract}
The expansion and improvement of the use of Virtual Learning Environments (VLEs) in Distance Education (ED) calls for the need for further discussion on the interactive potential of the tools, which constitute such environments. Thus, this research aims to verify the importance of interactivity and affectivity in the Moodle VLE as well as to delimit the possibilities and limitations in the development of teaching and learning at a distance, by using four Moodle tools. To achieve such objective, we have made a descriptive, bibliographic, and exploratory research. The results show how interactions between theparticipants of Distance Education are essential and, also, that students should receive affectionate treatment, as the sense of belonging contributes significantly to a proactive and collaborative learning. Keywords: Distance Education; Virtual Learning Environments; Moodle; Interactivity; Affection.
\end{abstract}




\section{Referências}

AMARAL, R.C.B.M.; ROSSINI A. M. Concepções de interatividade e tecnologia no processo de tutoria em programas de educação a distância: novos paradigmas na construção do conhecimento. Disponível em: <http://intersaberes.grupouninter.com. br/6/2.pdf> . Acesso em: 25 ago. de 2012.

ALMEIDA, M. E. B. Tecnologia e educação à distância: abordagens e contribuições dos ambientes digitais e interativos de aprendizagem. In: REUNIÃO ANUAL DA ANPED. Novo Governo. Novas Políticas, 26, 2003, Poços de Caldas, Minas Gerais. Disponível em: <http:www.anped.org.br/reunioes/26/trabalhos/mariaelizabethalmeida.rtf $>$. Acesso em: 10 Out. 2012.

ALVES, Lynn et al (Org.) Moodle: estratégias pedagógicas e estudo de caso. Salvador: EdUNEB, 2009. Disponível em: <http://www.moodle.ufba.br/file.php/1/Moodle_1911_ web.pdf.> Acesso em: 19 ago. 2012.

ANDERSON, Terry. Modes of Interaction in Distance Education: Recent Developments and Research Questions. In: MOORE, Michael G.; ANDERSON, William George (Editors). Handbook of Distance Education. 2003.

ABED - Associação Brasileira de Educação a Distância (Org.) Censo EaD.br. São Paulo: Pearson Education do Brasil, 2010.

BARBOSA, M. C. C. A interação, a interatividade e a linguagem: mediação e apoio ao ensino presencial através de um ambiente virtual de aprendizagem. 2005, 117f. Dissertação (Mestrado em Educação Tecnológica). Centro Federal de Educação Tecnológica de Minas Gerais, Belo Horizonte, 2005.

BARROS, Maria das Graças. A contribuição da interatividade nos Ambientes Virtuais de Aprendizagem Colaborativa. Disponível em: <http://www.ufpe.br/nehte/ simposio2008/anais/Maria-Gracas-Barros.pdf>. Acesso em: 12 set. 2012.

BONNATTO, MARTINS, RAMOS, SANTOS e SILVA. A importância da Afetividade nas Interações no contexto da Ead. Disponível em: <http://200.169.53.89/download/ CD\%20congressos/2008/V\%20ESUD/trabs/t38647.pdf>. Acesso em: 10 set. 2011.

GOMES, P.V. A experiência da PUC-PR na implantação das tecnologias de informação e comunicação no ensino superior. Colabora, Curitiba, v. 1, n. 1, p. 37-45, 2001. 
JÚNIOR, Celso P. S.; MASSENSSINE, Ariana. R., NEVES Cristiane d.R. B. Ações pedagógicas em um ambiente virtual de aprendizagem (AVA) Interatividade Vs evasão. Disponível em: < http://www.abed.org.br/congresso2010/cd/3042010192801. pdf>. Acesso em: 27 set. 2012.

LEVY, Pierre. O Que é o Virtual. São Paulo: Editora 34, 1996.

MATTAR, João. Guia de educação a distância. São Paulo: Cengage Learning: Portal Educação, 2011.

MOORE, Michael G. ; KEARSLEY, Greg. Educação a distância: uma visão integrada. (tradução Roberto Galman) São Paulo: Thomson Learning, 2007.

MUSSI Marcus; HAGUENAUER Cristina. Comunicação e Interatividade em AVA: um estudo de caso: Disponível em: <http://www.latec.ufrj.br/revistaeducaonline/vol3_3/2. pdf>. Acesso em: 04 out. 2012.

NAKAMURA, Rodolfo. Moodle: como criar um curso usando a plataforma de Ensino a Distância. São Paulo: Farol do Forte, 2009. Disponível em: <http://www.4shared.com/ document/7nG-n-EF/Moodle-como_criar_um_curso_u.html>. Acesso em: 2 set. 2012.

NARDIN, A.C.; FRUET, F. S. O.; BASTOS, F. P. Potencialidades tecnológicas e educacionais em ambiente virtual de ensino-aprendizagem livre. Novas tecnologias na Educação. CINTED-UFRGS, v. 7, n. 3, 2009.

PALLOF, R.M.; PRATT K. Construindo Comunidades de Aprendizagem. Tradução Vinícius Figueira. Porto Alegre: Artemed, 2002.

RONCARELLI, D. (2007). Pelas asas de Ìcaro: Construindo uma taxionomia para escolha de ambiente virtual de ensino - aprendizagem. 2007, 127f. Dissertação (Mestrado em Educação) - Centro de Ciências da Educação. Universidade Federal de Santa Catarina, Florianópolis, 2007.

SILVA, I. M.M.S. Ambiente Virtual de Aprendizagem na Educação a Distância. Disponível em: <http://www.conahpa.org/wp-content/themes/Conahpa/papers/ final98.pdf>. Acesso em: 11 out. 2012. 